\title{
An Analysis of Vegetation Change Trends and Their Causes in Inner Mongolia, China from 1982 to 2006
}

\author{
Baolin Li, ${ }^{1}$ Wanli Yu, ${ }^{1,2}$ and Juan Wang ${ }^{1,2}$ \\ ${ }^{1}$ State Key Lab of Resources and Environmental Information System, Institute of Geographical Sciences and Natural Resources Research, \\ Chinese Academy of Sciences, 11 Datun Road, Anwai, Chaoyang District, Beijing 100101, China \\ ${ }^{2}$ College of Resources and Environment, Graduate School of the Chinese Academy of Sciences, 19 Yuquan Road, Shijingshan District, \\ Beijing 100049, China \\ Correspondence should be addressed to Baolin Li, libl@lreis.ac.cn
}

Received 10 January 2011; Revised 2 April 2011; Accepted 9 June 2011

Academic Editor: Yasunobu Iwasaka

Copyright ( $) 2011$ Baolin Li et al. This is an open access article distributed under the Creative Commons Attribution License, which permits unrestricted use, distribution, and reproduction in any medium, provided the original work is properly cited.

This paper presents the vegetation change trends and their causes in the Inner Mongolian Autonomous Region, China from 1982 to 2006. We used National Oceanic and Atmospheric Administration (NOAA) Advanced Very High Resolution Radiometer (AVHRR) data to determine the vegetation change trends based on regression model by fitting simple linear regression through the time series of the integrated Normalized Difference Vegetation Index (NDVI) in the growing season for each pixel and calculating the slopes. We also explored the relationship between vegetation change trends and climatic and anthropogenic factors. This paper indicated that a large portion of the study area (17\%) had experienced a significant vegetation increase at the 0.05 level from 1982 to 2006. The significant vegetation increase showed no positive link with precipitation and was mainly caused by human activities. In or to the south of Horqin Sandy Land, in the Hetao Plain, and at the northern foothills of the YinshanMountain, the significant NDVI increase trends were mainly caused by the increase of the millet yield per unit of cropland. In the east of Ordos Plateau, the significant NDVI increase trends were mainly determined by the fencing and planting of grasses and trees on grassland.

\section{Introduction}

Desertification is one of the most serious regional environmental issues [1]. China is one of the major countries facing this problem in the world. The total area of desertificationprone land was approximately 2.62 million $\mathrm{km}^{2}$, occupying $27.3 \%$ of the total area of China [2]. The Inner Mongolian Autonomous Region, located in the north of China, is a typical agriculture-grazing transitional zone that has been seriously affected by desertification and has suffered from severe wind erosion and a high frequency of dust storms [3]. Thus, it is very important to determine the vegetation change trends for combating the desertification in this area.

With the accumulation of remotely sensed images over the past three decades, research on desertification based on monitoring vegetation change has been conducted from national to regional scales [4-9]. Fang et al. [4] and Piao et al. [5] reported that the vegetation in arid and semiarid areas of China increased significantly according to the analyses of NOAA/AVHRR data from 1982 to 1999 . These results suggested a reversal of the desertification processes in these regions. This research attributed the major cause of the vegetation increase to precipitation change. According to the research above, human activity was only responsible for a minor part of the change in vegetation increase. However, recent reports on a regional scale in China's $\mathrm{Mu}$ Us region indicated that the high increase of vegetation based on NOAA/AVHRR and Landsat Thematic Mapper (TM)/Enhanced Thematic Mapper (ETM) data had been mainly found to occur in irrigated farmland or in grassland dominated by human management $[6,7]$. Liu et al. [8] and Liu and Wang [9] reported that the vegetation degraded seriously in Otindag Sandy Land based on TM/ETM images before the 21st century, and their major causes were attributed to human activities.

These inconsistent results were first related to the difference in research scale. The research on a national scale was synoptical and did not express the specific vegetation 


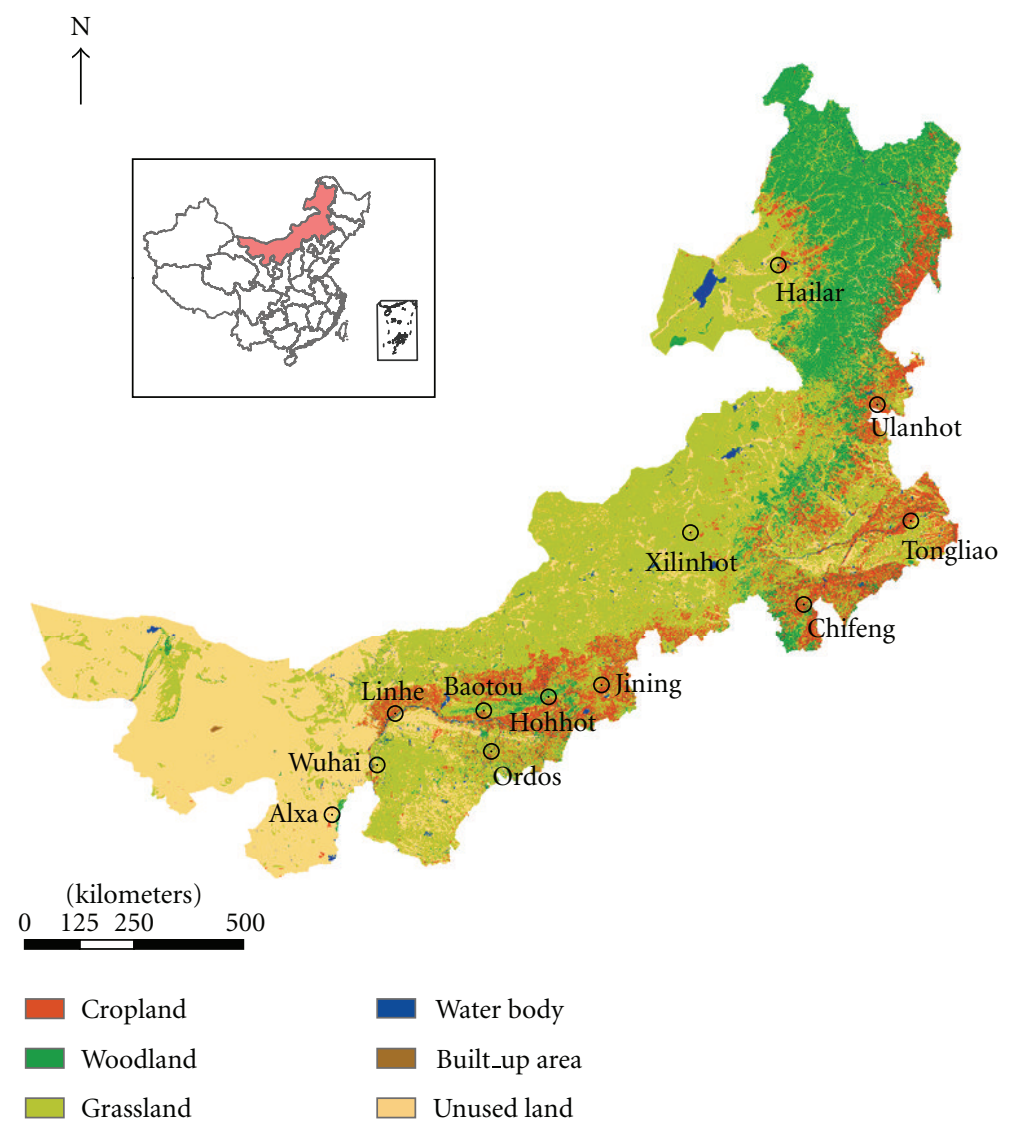

FIgURE 1: Study area and its land use in 2000 based on TM/ETM+ images.

changes and their causes on a regional scale. At the same time, due to the large size of the study area, most research on a national scale has not provided sufficient validation based on fieldwork and/or high spatial resolution remotely sensed data. If the vegetation changes and their causes will be understood more accurately, we must do more research work on a regional scale.

On the other hand, the inconsistent results were caused by the defects on the methodology of vegetation change detection on a regional scale. Desertification distributed in arid, semiarid, and dry subhumid areas. The high variation of annual precipitation is one of the fundamental environmental features in these areas and is therefore thought to cause high variation in vegetation [10]. The permanence of land degradation in the form of desertification is best determined by monitoring vegetation change in desertificationprone areas over a time scale of decades [11]. Because the determination of vegetation changes on a regional scale was mainly based on a few snapshot images, some vegetation variation caused by climatic fluctuation was mistakenly attributed to the vegetation change trends in the form of desertification [7].

In order to determine the vegetation change trends in the form of desertification and their causes accurately in the Inner Mongolian Autonomous Region, China, this study focused on two points: (1) analyzed the vegetation changes covering all the region on a regional scale; (2) determined the vegetation change trends in the form of desertification (not vegetation fluctuation) and their causes based on multitemporal NOAA/AVHRR NDVI, meteorological data, high spatial resolution remotely sensed images, and local economic statistical data from 1982 to 2006.

\section{Study Area}

The study area is the Inner Mongolian Autonomous Region, China, covering an area of $1,180,000 \mathrm{~km}^{2}$ and composed of 89 banners (counties or cities). The geographical coordinates are $97^{\circ} 12^{\prime} \sim 126^{\circ} 04^{\prime} \mathrm{E}, 37^{\circ} 24^{\prime} \sim 53^{\circ} 23^{\prime} \mathrm{N}$. Grassland is the main land use type, occupying more than $60 \%$ of the total area (Figure 1). The landscape is characterized by Mongolian Plateau, with a generally dry and harsh environment. The temperate, arid and semiarid, and continental climate is mainly governed by the southeast monsoon, with windy and dry winters and springs, and warm and comparatively wet summers, followed by short, cool autumns. Annual precipitation varies from $50 \mathrm{~mm}$ in the northwest to $450 \mathrm{~mm}$ in the southeast. Annual average temperature varies from $0^{\circ} \mathrm{C}$ to $8^{\circ} \mathrm{C}$. Soil types are black soil, chernozem, chestnut soil, and sandy soil from the east to the west. 


\section{Methodology}

3.1. Data and Preprocessing. 15-day maximum Global Inventory Modeling and Mapping Studies (GIMMS) NDVI data from 1982 to 2006 with $8 \mathrm{~km} \times 8 \mathrm{~km}$ spatial resolution were used. These data were obtained from NOAA, United States (http://www.noaa.gov/). These data were the sole remotely sensed data source with high temporal resolution suitable for vegetation change trend study over the study period. Although the $8 \mathrm{~km} \times 8 \mathrm{~km}$ spatial resolution was coarse, the general trend of vegetation change can be determined based on these data. For example, vegetation change trends based on NOAA AVHRR NDVI had been reported to be determined successfully in the African Sahel region [12-19].

The GIMMS NDVI data have been corrected for sensor degradation and intercalibration differences, global cloud cover contamination, viewing angle effects due to satellite drift, volcanic aerosols, and low signal-noise ratios due to subpixel cloud contamination and water vapor [20]. The original data were first reprojected using the Albers Conical Equal Area with parameters suitable for China, and then the 8 -bit NDVI Data were converted into real NDVI. Finally, the monthly maximum NDVI and the integrated monthly maximum NDVI in the growing season (May to September) were computed.

Monthly precipitation data of 134 meteorological stations in and within the $200 \mathrm{~km}$ buffer area of the study area from 1982 to 2006 were acquired from the China Meteorological Data Sharing Services System (http://data .cma.gov.cn/). Total precipitation in the growing season was computed for studying the relationship between vegetation change and precipitation. Finally, the gridded precipitation data with the same spatial resolution $(8 \mathrm{~km} \times 8 \mathrm{~km})$ as the NDVI data were obtained through spline interpolation.

We obtained land use data in 2000 for the study area from the China National Land Use Database established by the Chinese Academy of Sciences (CAS). The land use data were produced by visual interpretation using Landsat Thematic Mapper/Enhanced Thematic Mapper Plus (TM/ETM+) data. A two-level hierarchical classification system of 25 1st land use classes and 6 2nd land use classes was taken. We used the land use map based on 2nd level classification classes including cropland, woodland, grassland, water body, unused land, and built-up area. Because the overall accuracy of the land use classification in this database was quite high, with $92.9 \%$ for land use maps based on the 1st land use classification system [21], we believed that this dataset was accurate enough for examining the relationship between vegetation change and land use.

We also obtained the Standard Terrain Correction (Level 1T) TM/ETM+ images covering part of the Ordos Plateau (path/row: 128/033) in 1988 and 2010 from the United States Geological Survey (USGS) (http://landsat .usgs.gov/products_productinformation.php). The Level $1 \mathrm{~T}$ images were geometrically corrected and registered by incorporating ground control points while employing a digital elevation model (DEM) for topographic accuracy. Iterative Self-organizing data (ISODATA) technique was employed to classify each image independently to map the mobile sand dunes. The overall accuracy and kappa index based on confusion matrix were used as accuracy measures to assess the accuracies of the mobile sand dune maps [22]. A total of 300 sample points for each of the mobile sand dune map to be tested was generated based on a random sampling scheme. These sample points for each mobile sand dune map were then overlaid on the standard false color composite of Landsat TM/ETM+ (R: band 4, G: band 3, B: band 2). The mobile sand dune at each of these sample points was determined based on the visual interpretation of these composites.

Total cropland area and total millet yield for 89 banners (counties or cities) were obtained from local economic statistical datasets from 1982 to 2006. The millet yield per unit for each banner (county or city) was computed by dividing the total millet yield with the total cropland area.

\subsection{Determination of the Trends in Vegetation Change. NDVI} is sensitive to the presence, density, and condition of vegetation and is correlated with absorbed photosynthetically active radiation (PAR) and vegetation primary production [15]. It is particularly well suited to the study of vegetation changes in arid and semiarid regions [13]. Thus, we selected NDVI as an index to study vegetation change trends in this research.

There are some commonly used NDVI indices to present vegetation change, including ten-day maximum NDVI, monthly maximum NDVI, annual maximum NDVI, integrated ten-day maximum NDVI in the growing season, and integrated monthly maximum NDVI in the growing season [12-19]. In this study, the integrated monthly maximum NDVI in the growing season (May to September) was used. The selection of this index was based on two points: (1) integrated monthly maximum NDVI in the growing season can better reflect the holistic conditions of vegetation than the ten-day maximum NDVI, monthly maximum NDVI, or annual maximum NDVI because of the high interseasonal variation of vegetation in arid and semiarid zones; (2) integrated monthly maximum NDVI in the growing season was affected by cloud contamination less than the integrated ten-day maximum NDVI in the growing season.

The overall trend in vegetation change over the period from 1982 to 2006 was determined based on the time series of the integrated monthly maximum NDVI in the growing season by fitting simple linear regression using least squares estimation (dependent variable: integrated NDVI; independent variable: time) [23]. The overall trends were then converted into change rate in integrated NDVI throughout the study period and expressed as a percentage relative to the value of the linear trend line at the starting point of the time series. F-statistics was used to determine the significance of linear regression models. Finally, the maps of integrated NDVI change trend and $F$-statistics value were overlapped to determine the significant vegetation changes. If the regression model was significant at the 0.05 level, the integrated NDVI was considered to indicate the increase or decrease trend. 
TABLE 1: The percentage of different vegetation change trends to the total study area $(\%)$.

\begin{tabular}{cccccccc}
\hline \multicolumn{4}{c}{ Increase significantly } & \multicolumn{4}{c}{ Decrease significantly No trend } \\
& $>15$ & $0-15$ & Total & $>15$ & $0-15$ & Total & \\
\hline Percentage & 12.66 & 4.02 & $\mathbf{1 6 . 6 8}$ & 1.45 & 1.97 & $\mathbf{3 . 4 2}$ & 79.90 \\
\hline
\end{tabular}

3.3. Determination of the Driving Factors of Vegetation Change Trends. The Inner Mongolian Autonomous Region was mainly located in the arid and semiarid zones. The precipitation was the major natural factor which limited the vegetation grown-up in arid and semiarid zones, especially in the growing seasons. Although the climatic factors such as temperature, evaporation, and solar radiation do have impact on vegetation grown-upness, they do not play limiting roles in arid and semiarid zones over the growing seasons. Other natural factors such as soil and landform do not change much on a decade scale and thus will not affect vegetation change much, too. In order to simplify the analysis of the causes of vegetating change trends, we only considered precipitation (the major limiting factor in arid and semiarid zones) as the sole natural factor which affected the vegetation change in the growing seasons.

Pearson's correlation coefficients for each pixel were computed to test the strength of the linear association between precipitation and NDVI. The integrated monthly maximum NDVI in the growing season and the accumulated precipitation over the same period were used to find their relationship. If Pearson's correlation coefficients between these two variables for most pixels in a region were correlated significantly at the 0.05 level, precipitation was considered as the major cause of vegetation change trends in this region. If Pearson's correlation coefficients between these two variables for most pixels in a region were correlated insignificantly at the 0.05 level, we considered that the vegetation change trends in this region were mainly caused by nonclimatic factors.

In the regions where vegetation change trends were mainly caused by nonclimatic factors, the relationship between vegetation change and land use was determined. The land use map based on Landsat TM/ETM+ in 2000 was overlapped with the vegetation change trend map based on GIMMS integrated NDVI data. If there was a significant increase of integrated NDVI occurring in the area where cropland was distributed, it was likely that the vegetation increase was caused by human activities. If there was a significant increase of integrated NDVI occurring in the area where the mobile sand dunes were converted to other land use types such as grassland, forest, or cropland, the vegetation increase was also attributed to human activities.

\section{Results and Discussion}

4.1. Vegetation Change Trends. During the period from 1982 to $2006,17 \%$ of the study area showed a significant vegetation increase, while $3 \%$ showed a significant decrease at the 0.05 level according to the F-statistic values (Table 1). Other regions had no significant vegetation change trend. In
TABLE 2: The percentage of different correlations between integrated NDVI in the growing season and accumulated precipitation over the same period for each land use type to the total study area (\%).

\begin{tabular}{lccc}
\hline & $\begin{array}{c}\text { Positive } \\
\text { significant }\end{array}$ & $\begin{array}{c}\text { Negative } \\
\text { significant }\end{array}$ & $\begin{array}{c}\text { None } \\
\text { significant }\end{array}$ \\
\hline Cropland & 26.09 & 0.13 & 73.78 \\
Woodland & 1.02 & 4.44 & 94.54 \\
Grassland & $\mathbf{5 8 . 0 2}$ & 0.04 & 41.94 \\
Unused land & 20.29 & 0.56 & 79.16 \\
Whole area & 33.31 & 0.90 & 65.79 \\
\hline
\end{tabular}

approximately $13 \%$ of the study area, the integrated NDVI indicated a strong significant increase (more than 15\%). These results indicated that quite a large portion of the study area had experienced a significant vegetation increase, and only a small part had significantly showed vegetation decrease over the study period.

The spatial pattern of vegetation change trends clearly varied in the study area. The area where integrated NDVI significantly increased mainly distributed in four regions (Figure 2). One was in or to the south of Horqin Sandy Land (region I), including Horqin Zuoyi Zhong Banner, Kailu County, Tongliao City, Horqin Zuoyi Hou Banner, Naiman Banner, Ongmud Banner, Hure Banner, Aohan Banner, Chifeng City, Harqin Banner, Ningcheng County (ID: 24, 29, $30,32,34,35,36,39,42,47,50)$. The second was in the Hetao Plain (region II), including Wuyuan County, Linhe County, Hangjin Hou Banner, Tumd Zuoqi Banner, Tumd You Banner, Dengkou County (ID: 69, 70, 71, 72, 75, 76). The third was at the northern foothills of the Yinshan Mountain (region III), including Shangdu County, Qahar Youyi Hou Banner, Qahar Youyi Zhong Banner, Xinghe County, Qahar Youyi Qian Banner, Fengzhen County, Liangcheng County (ID: 53, 55, 56, 61, 64, 73, 74). The fourth was in the east of Ordos Plateau (region IV), including Horinger Banner, Dalad Banner, Jungar Banner, Qingshuihe County, Ordos City, Ejin Horo Banner, Uxin Banner (ID: 79, 81, 82, 83, 85, $87,88)$.

\subsection{Driving Factors of Vegetation Change Trends}

4.2.1. Relationship between Integrated NDVI and Precipitation. Figure 3 showed the spatial pattern of the correlation coefficients between integrated NDVI in the growing season and accumulated precipitation over the same period. The pattern varied clearly across the entire study area from 1982 to 2006. Where integrated NDVI showed significant increase trend, the correlation coefficients were insignificant at 0.05 level (ID: 24, 29, 30, 32, 34, 35, 36, 39, 42, 47, 50, 53, 55, 56, $61,64,69,70,71,72,73,74,75,76,79,81,82,83,85,87,88)$ (Table 2).

The correlation coefficients were insignificant in the area where NDVI showed significant increase trends; therefore precipitation was not the major cause of the significant increase trends in integrated monthly maximum NDVI in 
TABLE 3: The percentage of different land uses to the total area in the regions where NDVI had strong increasing trends (\%).

\begin{tabular}{|c|c|c|c|c|c|c|}
\hline & Cropland & Woodland & Grassland & Water body & Built-up area & Unused land \\
\hline Region I & 45.94 & 7.45 & 31.05 & 2.34 & 3.07 & 10.16 \\
\hline Region II & 42.37 & 1.56 & 21.07 & 2.10 & 9.66 & 23.24 \\
\hline Region III & 50.69 & 6.88 & 31.79 & 2.74 & 4.74 & 3.17 \\
\hline Region IV & 12.52 & 4.24 & 57.51 & 3.09 & 1.71 & 20.92 \\
\hline
\end{tabular}

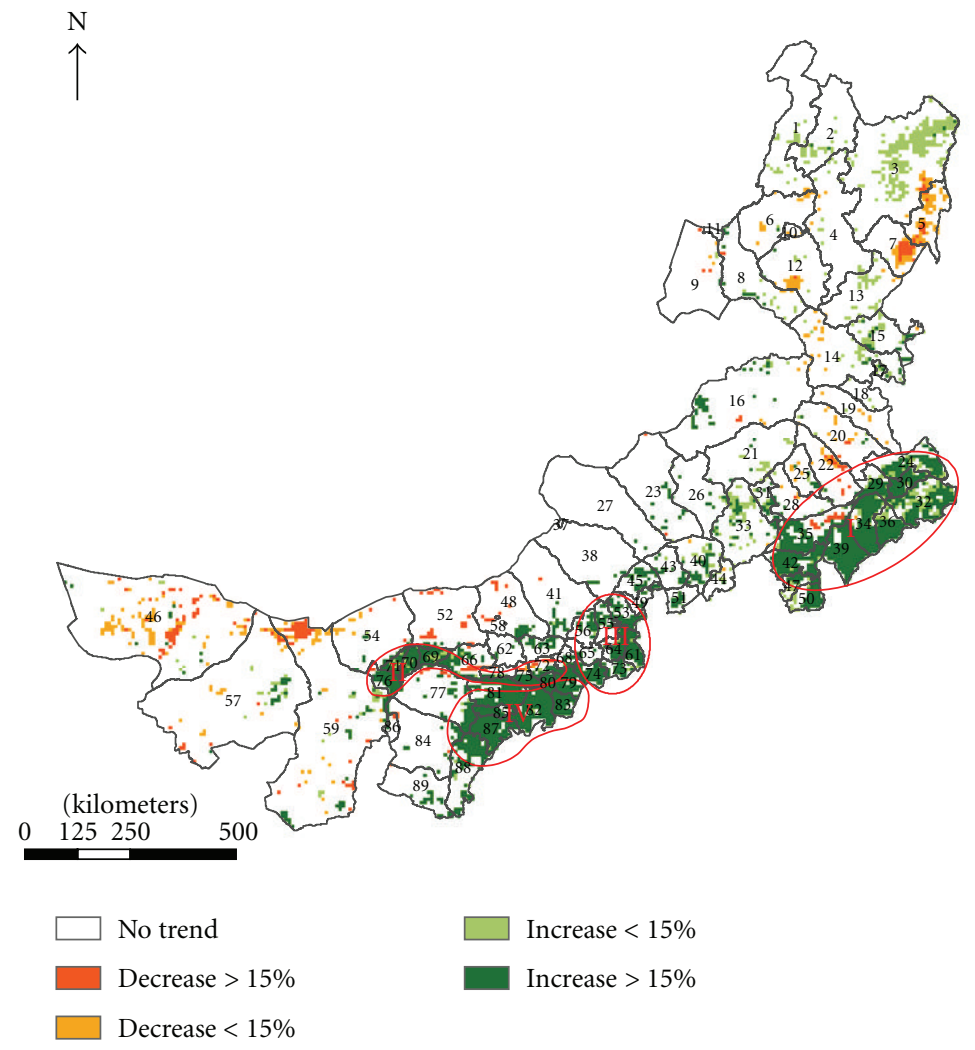

FIGURE 2: Overall trends in vegetation changes throughout the period 1982-2006. Percentages expressed changes in integrated monthly maximum GIMMS NDVI during the growing season over the study period. The significance of regression models was at the 0.05 level. $16.7 \%$ of the study area showed a significant increase trend. The area where integrated NDVI significantly increased mainly distributed in four regions: I (Banner or county ids: 24, 29, 30, 32, 34, 35, 36, 39, 42, 47, 50), II (Banner or county ids: 69, 70, 71, 72, 75, 76), III (Banner or county ids: 53, 55, 56, 61, 64, 73, 74), IV (Banner or county ids: 79, 81, 82, 83, 85, 87, 88).

the growing season. These results suggested that there was no positive link between the significant vegetation increases and precipitation change as frequently reported in the African Sahel region and China on continental or national scales $[4,5,12-19]$.

It should be pointed that there were positive correlations between NDVI and precipitation in quite a lot of areas (ID: $6,8,9,10,11,12,16,21,23,26,27,37,38,41,48,43,45,53$, $55,56,65,63,62,58,48)$. In these areas, the integrated NDVI showed no significant change trends and mainly distributed on grassland (Figures 1 and 3). The human activities only have minor impact on the vegetation change in these areas, and thus it was not surprising that the precipitation plays key role in vegetation changes.
4.2.2. Relationship between Integrated NDVI and Human Activities. The vegetation increase trends in region I, II, III were mainly related to the change of cropland. Most land in these regions was used as cropland, which occupied $45.9 \%$, $42.4 \%$, and $50.7 \%$ of the total area, respectively (Table 3 ). The increase in the integrated NDVI over the growing season was caused by the increase in the biomass of cropland with the improvement of human management such as irrigation and fertilizer. Table 4 showed that the millet yield per unit showed significant increase trend at the 0.05 level in almost all of these regions. The increase in millet yield per unit indicated the increase in crop biomass. Thus, we believed that the biomass of cropland increased significantly over the study period. Therefore, it was not surprising to observe that 


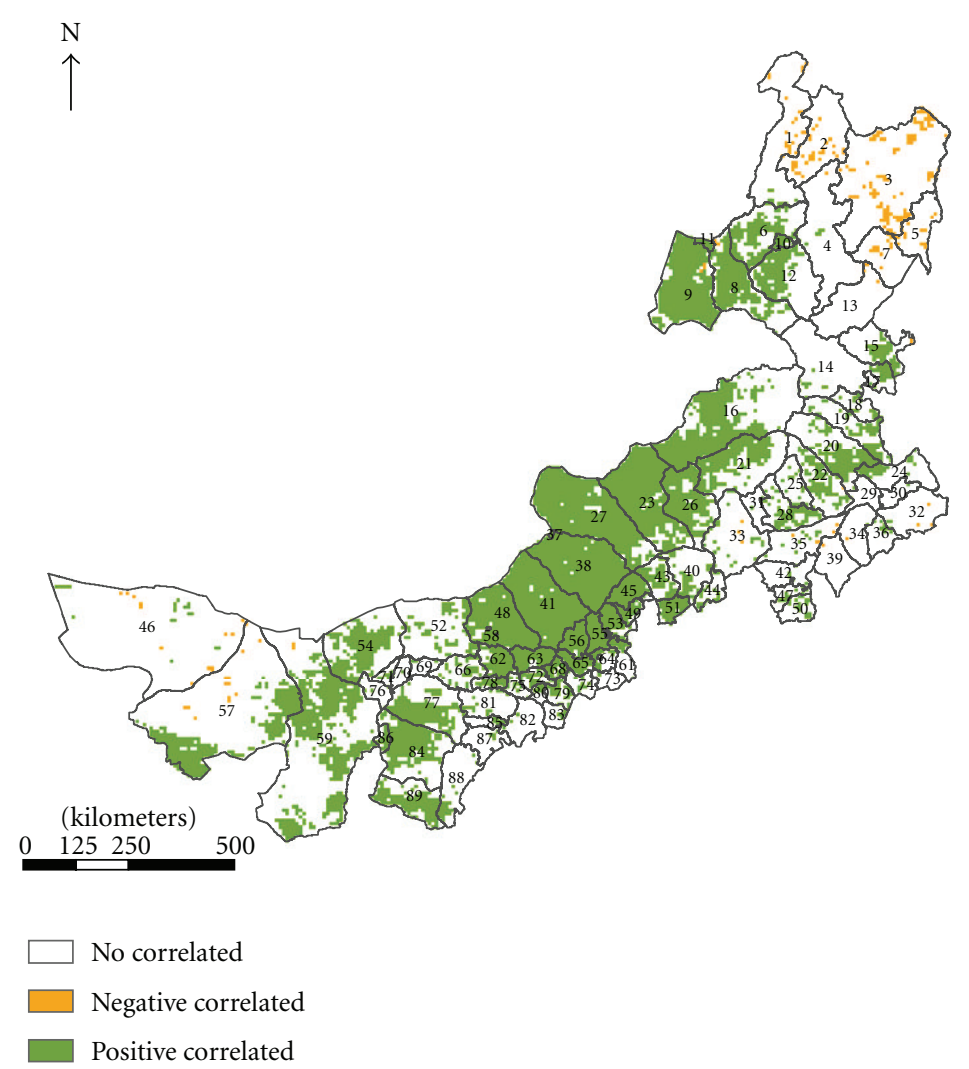

FIGURE 3: The correlation coefficients between the integrated NDVI in the growing season and the accumulated precipitation over the same period. The significance of correlation model was at the 0.05 level. Where NDVI showed significant increase trend, the correlation coefficients were not significant (Banner or county ids: 24, 29, 30, 32, 34, 35, 36, 39, 42,47,50, 53, 55, 56, 61, 64, 69, 70, 71, 72, 73, 74, 75, 76, 79, 81, 82, $83,85,87,88$ ), while where NDVI showed no significant change trends, the correlation coefficients were significant (Banner or county ids: $6,8,9,10,11,12,16,21,23,26,27,37,38,41,48,43,45,53,55,56,65,63,62,58,48)$.

TABLE 4: The slope and F-statistics value of linear regression model of millet yield per unit $\left(t / h a \times 10^{4}\right)$.

\begin{tabular}{lcc}
\hline County (city or banner) & Slope & $F$-value \\
\hline Horqin Zuoyi Zhong & 0.09 & $17.1^{*}$ \\
Kailu & 0.19 & $55.2^{*}$ \\
Horqin Zuoyi Hou & 0.08 & $25.2^{*}$ \\
Naiman & 0.11 & $56.1^{*}$ \\
Hure & 0.07 & $42.5^{*}$ \\
Aohan & 0.07 & $15.7^{*}$ \\
Ongniud & 0.11 & $76.8^{*}$ \\
Ningcheng & 0.18 & $78.5^{*}$ \\
Harqin & 0.06 & $19.9^{*}$ \\
Wuyuan & 0.05 & $19.8^{*}$ \\
Hanggin Hou & 0.06 & $12.3^{*}$ \\
Dengkou & -0.05 & $6.0^{*}$ \\
Ejin Horo & 0.08 & $33.5^{*}$ \\
Liangcheng & 0.11 & $45.1^{*}$ \\
\hline
\end{tabular}

${ }^{*}$ Regression model can reach the significance at the 0.05 level.

in most of these regions where the integrated NDVI in the growing season increased significantly, the major land use type was cropland.
TABLE 5: The overall accuracy of the moving sand dune maps.

\begin{tabular}{lcc}
\hline Index & $15 / 09 / 1988$ & $10 / 07 / 2010$ \\
\hline Overall accuracy $(\%)$ & 98 & 90 \\
Kappa coefficient & 0.89 & 0.74 \\
\hline
\end{tabular}

The NDVI changes in region IV where NDVI increased significantly were mainly caused by the fencing and planting of grasses and trees in these areas. Figure 4 showed that the mobile sand dunes had decreased rapidly in part of this region during the period from 1988 to 2010 . The area of the mobile dune decreased over $50 \%$ from $6790 \mathrm{~km}^{2}$ in 1988 to $2753 \mathrm{~km}^{2}$ in 2000 (the overall accuracies of classification ranged from $90 \%$ to $98 \%$, kappa coefficients ranged from 0.74 to 0.89 as shown in Table 5). The decrease of the mobile sand dunes indicated the increase of biomass in this region over the study period. Thus, the integrated NDVI showed the significant increase trend.

\section{Conclusion}

This paper indicated the long-term change of vegetation increase from 1982 to 2006 in a large portion of the Inner 


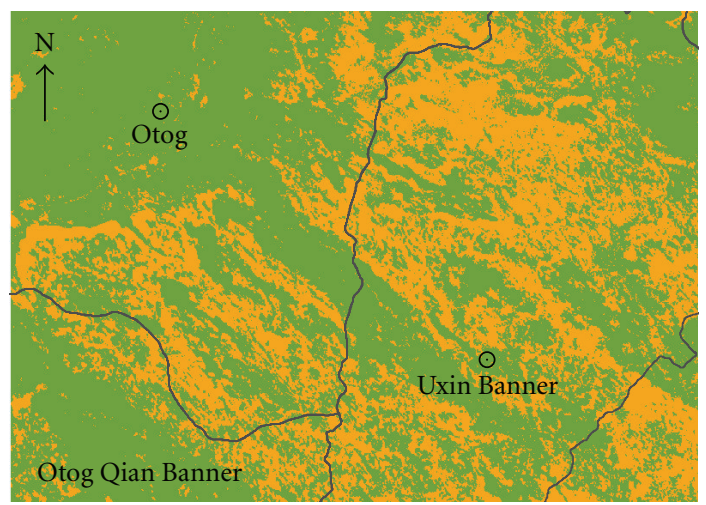

(a)

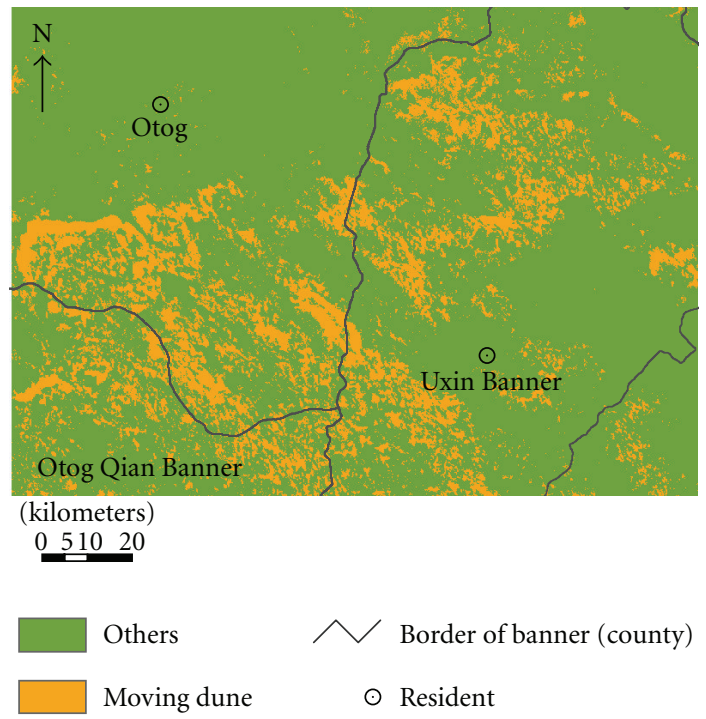

(b)

FIGURE 4: The spatial pattern of moving sand dune in part of Ordos Plateau in 15/09/1988 and 10/07/2010. The area of moving sand dune in 1988 was $6790 \mathrm{~km}^{2}$ and decreased to $2753 \mathrm{~km}^{2}$ in 2010 .

Mongolian Autonomous Region, China. 17\% of the study area showed a significant increase trend at the 0.05 level according to the F-statistic value. These results were similar to those of vegetation changes which had been frequently reported on continental or national scales in the African Sahel region and in China [4, 5, 12-19].

This paper also indicated that the significant vegetation increase showed no obvious positive link with the precipitation in the study area. In the region where NDVI showed significant increase, the integrated monthly maximum NDVI in the growing season and the accumulated precipitation over the same period were insignificant at the 0.05 level. These results were different from those on the relationship between vegetation and precipitation, which had been reported on continent or national scales in the African Sahel region and in China. The previous research mainly attributed the vegetation increase to precipitation change [4, 5, 12-19].

The increase of integrated monthly maximum NDVI in the growing season was mostly related to human actives. The significant NDVI increase trends were mainly caused by the increase of the millet yield per unit of cropland in or to the south of Horqin Sandy Land, in the Hetao Plain, and at the northern foothills of the Yinshan Mountain (Region I, II, III). In the east of Ordos Plateau (region IV), significant NDVI increase trends were mainly caused by the fencing and planting of grasses and trees on the grassland.

\section{References}

[1] D. S. G. Thomas, "Science and the desertification debate," Journal of Arid Environments, vol. 37, no. 4, pp. 599-608, 1997.

[2] Chinese Committee for Implementing UN Convention to Combat Desertification (CCICCD), China Country Paper to Combat Desertification, China Forestry Publishing House, Beijing, China, 1997.

[3] X. M. Wang, F. H. Chen, and Z. B. Dong, "The relative role of climatic and human factors in desertification in semiarid China," Global Environmental Change, vol. 16, no. 1, pp. 4857, 2006.

[4] J. Y. Fang, S. L. Piao, J. S. He, and W. H. Ma, "Increasing terrestrial vegetation activity in China, 1982-1999," Science in China C, vol. 47, no. 3, pp. 229-240, 2004.

[5] S. Piao, J. Fang, H. Liu, and B. Zhu, "NDVI-indicated decline in desertification in China in the past two decades," Geophysical Research Letters, vol. 32, no. 6, pp. 1-4, 2005.

[6] M. C. Runnström, "Is northern China winning the battle against desertification? Satellite remote sensing as a tool to study biomass trends on the ordos plateau in semiarid China," AMBIO, vol. 29, no. 8, pp. 468-476, 2000.

[7] M. C. Runnström, "Rangeland development of the Mu Us Sandy Land in semiarid China: an analysis using landsat and NOAA remote sensing data," Land Degradation and Development, vol. 14, no. 2, pp. 189-202, 2003.

[8] H. J. Liu, C. H. Zhou, W. M. Cheng, E. Long, and R. Li, "Monitoring sandy desertification of Otindag Sandy Land based on multi-date remote sensing images," Acta Ecologica Sinica, vol. 28, no. 2, pp. 627-635, 2008.

[9] S. Liu and T. Wang, "Aeolian desertification from the mid1970 s to 2005 in Otindag Sandy Land, Northern China," Environmental Geology, vol. 51, no. 6, pp. 1057-1064, 2007.

[10] M. Kassas, "Desertification: a general review," Journal of Arid Environments, vol. 30, no. 2, pp. 115-128, 1995.

[11] S. M. Herrmann, A. Anyamba, and C. J. Tucker, "Recent trends in vegetation dynamics in the African Sahel and their relationship to climate," Global Environmental Change, vol. 15, no. 4, pp. 394-404, 2005.

[12] L. Jarlan, S. Mangiarotti, E. Mougin, P. Mazzega, P. Hiernaux, and V. Le Dantec, "Assimilation of SPOT/VEGETATION NDVI data into a sahelian vegetation dynamics model," Remote Sensing of Environment, vol. 112, no. 4, pp. 1381-1394, 2008.

[13] L. Olsson, L. Eklundh, and J. Ardö, "A recent greening of the Sahel-Trends, patterns and potential causes," Journal of Arid Environments, vol. 63, no. 3, pp. 556-566, 2005.

[14] A. Anyamba and C. J. Tucker, "Analysis of Sahelian vegetation dynamics using NOAA-AVHRR NDVI data from 1981-2003," Journal of Arid Environments, vol. 63, no. 3, pp. 596-614, 2005.

[15] S. M. Herrmann, A. Anyamba, and C. J. Tucker, "Recent trends in vegetation dynamics in the African Sahel and their relationship to climate," Global Environmental Change, vol. 15, no. 4, pp. 394-404, 2005. 
[16] C. O. Justice, B. N. Holben, and M. D. Gwynne, "Monitoring East African vegetation using AVHRR data," International Journal of Remote Sensing, vol. 7, no. 11, pp. 1453-1474, 1986.

[17] S. E. Nicholson, M. L. Davenport, and A. R. Malo, "A comparison of the vegetation response to rainfall in the Sahel and East Africa, using normalized difference vegetation index from NOAA AVHRR," Climatic Change, vol. 17, no. 2-3, pp. 209-241, 1990.

[18] N. Martiny, P. Camberlin, Y. Richard, and N. Philippon, "Compared regimes of NDVI and rainfall in semi-arid regions of Africa," International Journal of Remote Sensing, vol. 27, no. 23, pp. 5201-5223, 2006.

[19] S. Chamaille-Jammes, H. Fritz, and F. Murindagomo, "Spatial patterns of the NDVI-rainfall relationship at the seasonal and interannual time scales in an African savanna," International Journal of Remote Sensing, vol. 27, no. 23, pp. 5185-5200, 2006.

[20] J. Pinzon, M. E. Brown, and C. J. Tucker, "Satellite time series correction of orbital drift artifacts using empirical mode decomposition," in Hilbert-Huang Transform: Introduction and Applications, N. Huang, Ed., pp. 167-186, 2005.

[21] J. Liu, M. Liu, H. Tian et al., "Spatial and temporal patterns of China's cropland during 1990-2000: an analysis based on Landsat TM data," Remote Sensing of Environment, vol. 98, no. 4, pp. 442-456, 2005.

[22] R. G. Congalton and K. Green, In Assessing the Accuracy of Remotely Sensed Data: Principles and Practices, Lewis Publishers, Boca Raton, Fla, USA, 1999.

[23] G. Shaw and D. Wheeler, Statistical Techniques in Geographical Analysis, John Wiley \& Sons, Chichester, UK, 1985. 

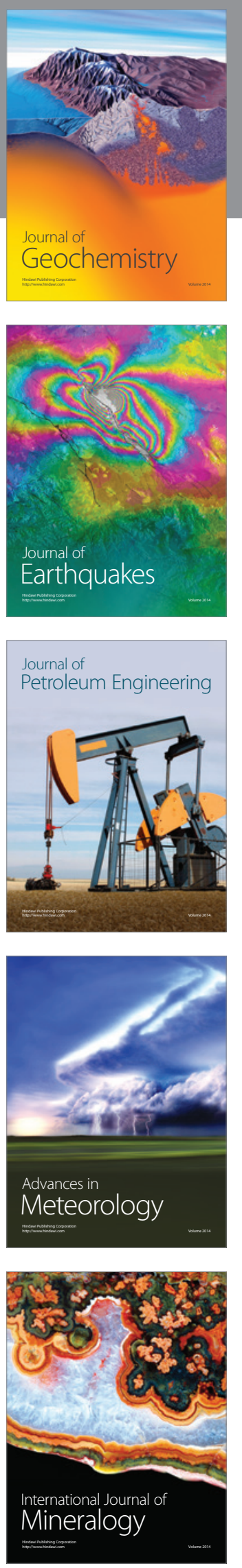
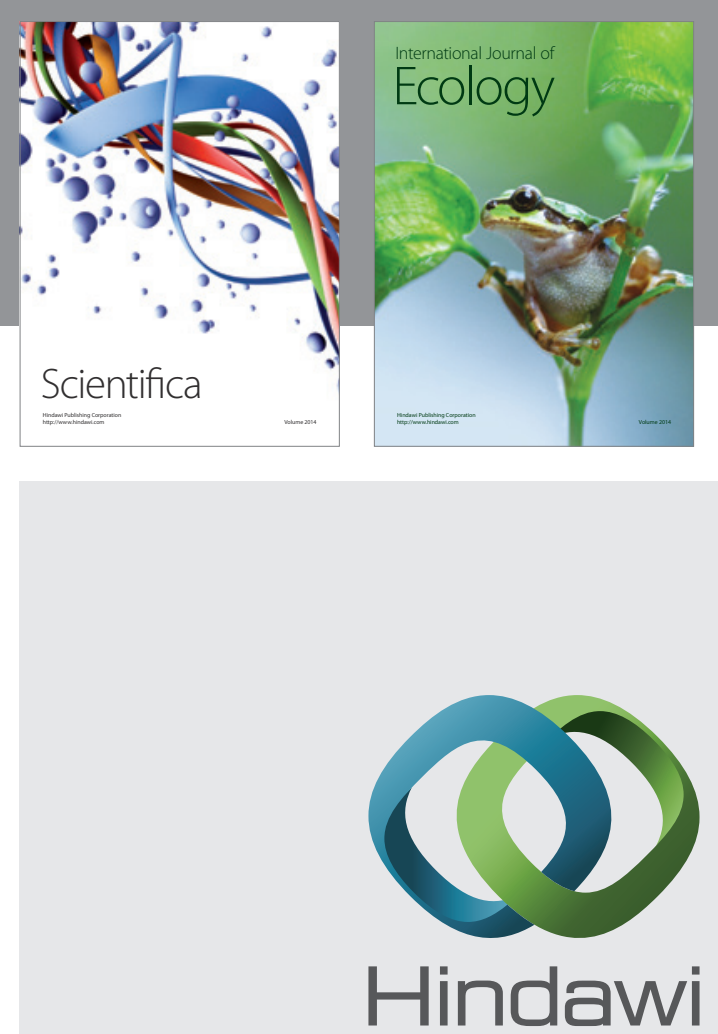

Submit your manuscripts at http://www.hindawi.com
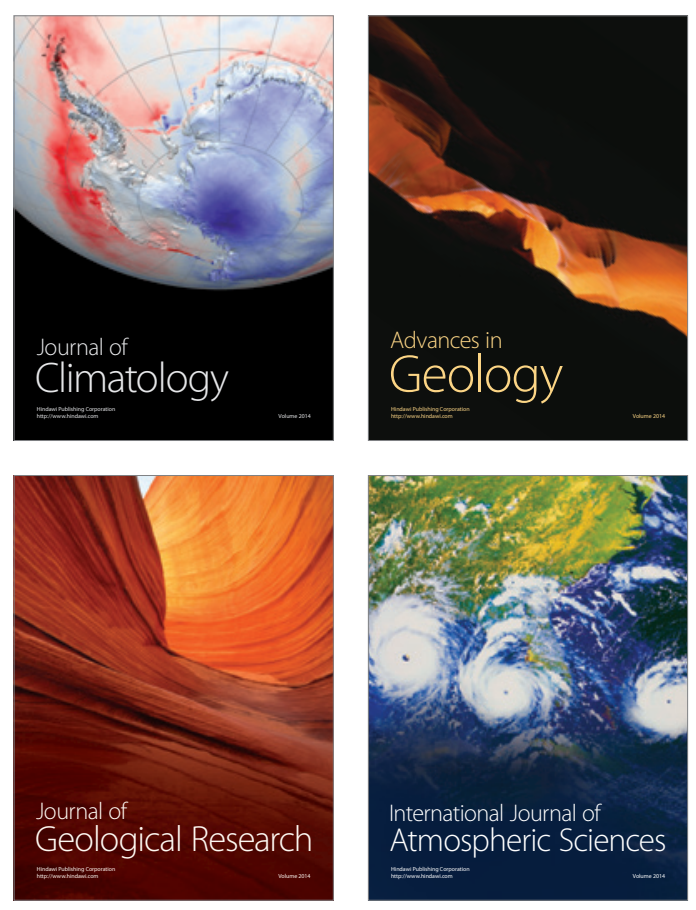
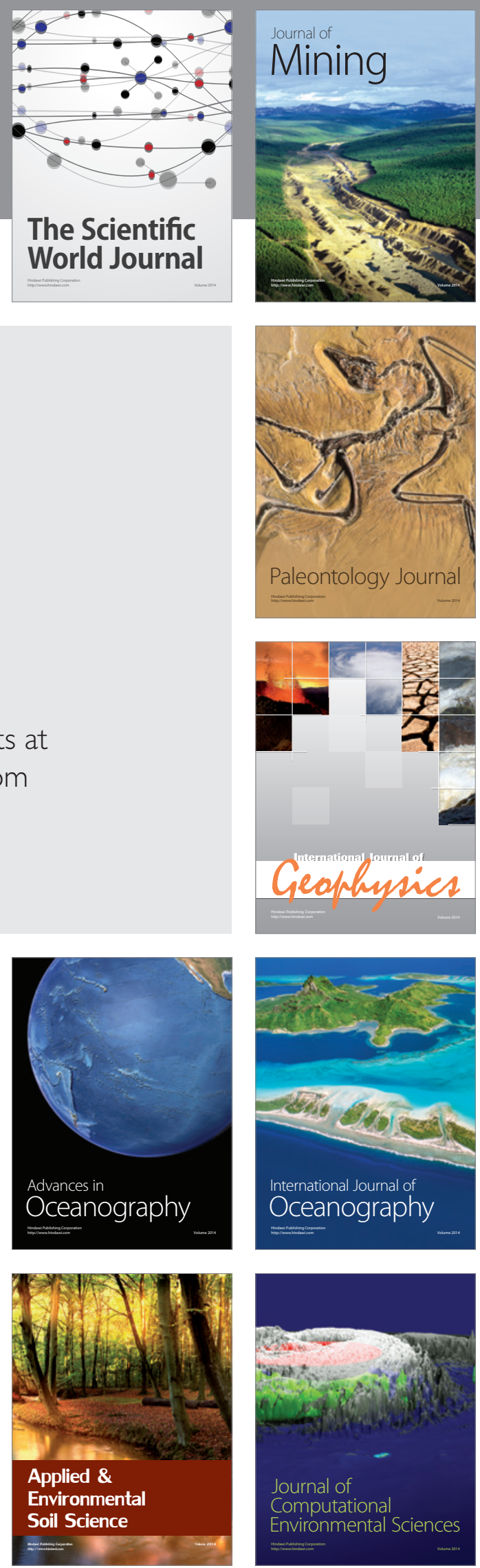